\title{
Optimalisasi Pemanfaatan Ruang Luar Kampus ITSB Deltamas melalui Penelitian Persepsi dan Harapan Sivitas Akademik
}

\author{
Esti Galuh Arini ${ }^{1}$ \\ 1. Arsitektur, Fakultas Teknik \& Desain, Institut Teknologi Sains Bandung, Cikarang, Indonesia \\ E-mail: estigaluharini@gmail.com
}

Informasi naskah:

Diterima

15 Desember 2019

Direvisi

17 Januari 2020

Disetujui terbit

14 Februari 2020

Diterbitkan

28 Februari 2020

\begin{abstract}
Many college campuses in Indonesia are designed so that the academic civitas, especially students, feel at home in their activities. The length of stay of students on campus is one important factor in supporting the success of the learning process. Therefore, the design of the campus outdoor space in accordance with the expectations of its users must be considered to support this. For the case study, research was carried out at the Bandung Institute of Technology and Science (ITSB) in the City of Deltamas, Cikarang, West Java. In the near future ITSB Deltamas will have two new buildings: the Container Building as an additional classroom and the Student Dormitory Building, in addition to the Main Campus Building which is the place for all current academic activities now. However, the campus outdoor space has not been well planned, so the use of the space has not been optimal. Optimizing the use of offcampus space is obtained through research of perceptions and expectations aimed at formulating the needs and desires of the academic civitas of ITSB Deltamas by finding the types of activities and facilities that best suit the needs and desires of its users. The results of this study are the design criteria of the ITSB Deltamas outdoor space which can be a recommendation in the field of outdoor space supply planning as an integral part of future campus planning. It is expected that by creating programs and design criteria that meet the needs and desires of the ITSB Deltamas academic civitas as end users, it will create an outdoor campus space design that is responsive to wants and needs (responsive), has emotional ties (meaningful), and can be used by all users (democratic).
\end{abstract}

Keywords: campus planning, campus outdoor space, design criteria, participatory research, ITSB, Kota Deltamas. 


\section{PENDAHULUAN}

Kampus ITSB menempati area seluas $5 \mathrm{Ha}$, di Central Bussines Distric Kota Deltamas, Cikarang Pusat, Kabupaten Bekasi. Pada area kampus ini rencananya akan dibangun 10 blok gedung untuk fasilitas akademik dan non akademik ITSB.

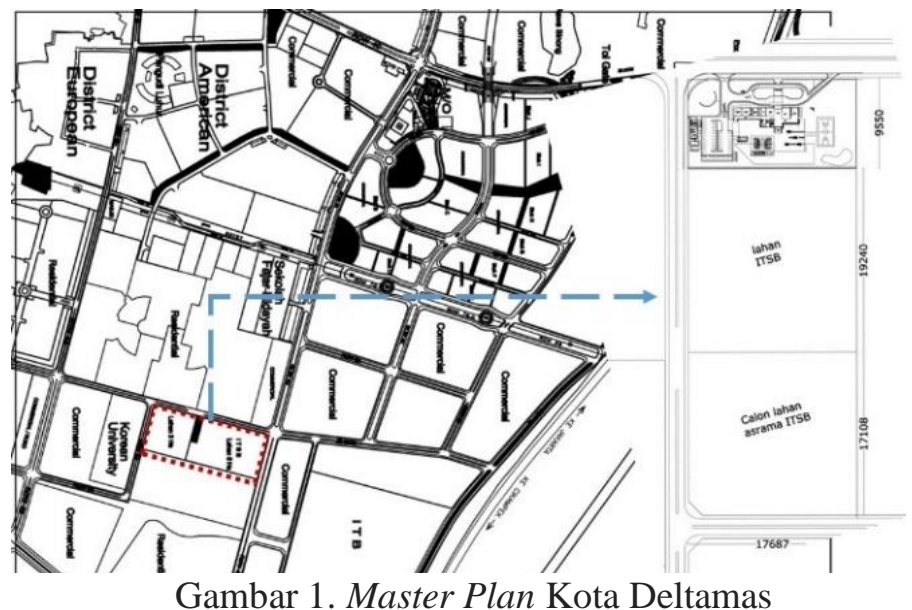

Dari 5 Ha lahan yang diperuntukkan sebagai kampus, baru sekitar $20 \%$ saja yang dibangun dan dikembangkan. Kampus ITSB memiliki empat bangunan, yaitu: gedung utama, gedung kontainer, gedung workshop, serta bangunan utilitas dan keamanan.

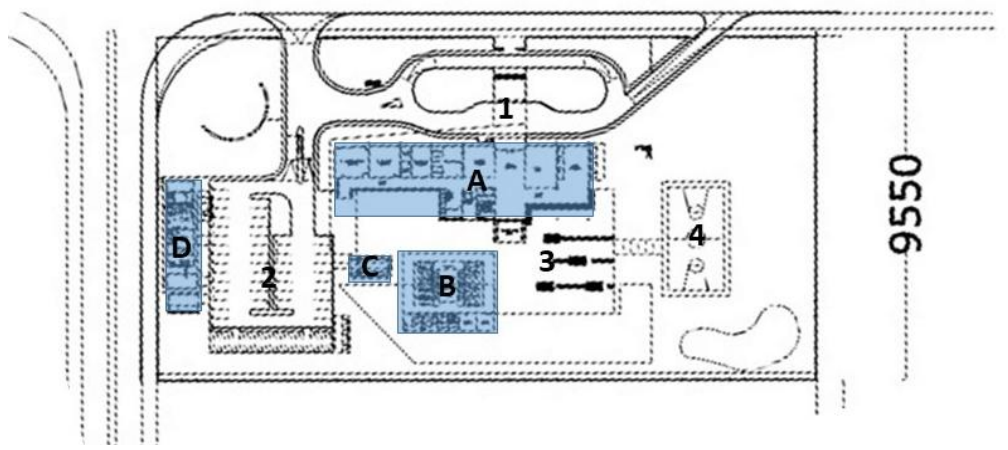

LEGENDA:

A. GEDUNG UTAMA

B. GEDUNG KONTAINER

C. WORKSHOP

D. UTILITAS \& SATPAM

1. DROP OFF

2. PARKIR

3. PLAZA KAMPUS

4. LAPANGAN BASKET

Gambar 2. Ground Plan ITSB.

Ruang luar dan ruang antarbangunan yang ada dimanfaatkan sebagai:

1. Area hijau dan area drop off di sisi utara

2. Parkir kendaraan di sisi barat

3. Area hijau dan plaza kampus di sisi selatan

4. Lapangan basket di sisi barat. 
Meski secara zonasi cukup jelas, namun ruang luar kampus ITSB ini belum dimanfaatkan secara maksimal oleh sivitas akademik. Dikarenakan ruang-ruang hijau dan ruang antar bangunan yang ada hanyalah ruang-ruang pasif yang tidak bisa digunakan untuk beraktivitas. Begitupun dengan plaza kampus yang terbatas waktu penggunaannya. Karena tidak cukup peneduhan dan pembayangan, maka plaza utama yang diisi dengan meja dan bangku panjang ini baru bisa digunakan saat sore hari. Itu pun tidak lama, karena sivitas akademik harus berkejaran dengan senja. Begitu matahari tenggelam, area ini tak bisa digunakan karena penerangannya tidakcukup memadai untuk beraktivitas. Padahal sivitas akademik kekurangan ruang-ruang untuk beraktivitas, baik aktif maupun pasif, juga bersosialisasi.

Gedung utama kampus yang didominasi ruang-ruang kelas dan penunjangnya hanya bisa digunakan untuk kegiatan perkuliahan saja. Sementara gedung kontainer yang direncanakan sebagai gedung perkuliahan tambahan, belum bisa dipergunakan karena pembangunannya yang belum rampung. Akibatnya, sivitas akademik hanya memiliki ruang luar kampus yang bisa mereka gunakan untuk berkegiatan dan bersosialisasi. Desain dan perencanaan ruang luar ini belum matang, sehingga sivitas akademik pun tidak bisa memanfaatkannya secara optimal. Karena itu, ruang luar kampus ITSB Deltamas perlu direncanakan dengan baik demi kesuksesan proses pembelajaran.

Rumusan permasalahan penelitian:

1. Bagaimanakah potensi ruang luar kawasan kampus ITSB Deltamas ditinjau dari aspek pemanfaatan ruang sesuai dengan fungsi kampus sebagai pusat pendidikan, penelitian dan pengabdian kepada masyarakat?

2. Seperti apakah persepsi dan harapan sivitas akademik terhadap ruang luar kampus ITSB Deltamas?

3. Bagaimana merumuskan program dan kriteria desain ruang luar kampus ITSB Deltamas yang tanggap terhadap kebutuhan pengguna (sivitas akademik)?

Dengan menggabungkan hasil rumusan kebutuhan dan keinginan sivitas akademik yang didapatkan lewat penelitian, hasil analisis pada lahan serta kajian literatur yang telah dilakukan sebelumnya, maka bisa didapatkan optimalisasi pemanfaatan dan bentuk ruang luar kampus yang sesuai dengan keinginan dan kebutuhan sivitas akademik untuk dikembangkan pada lahan kampus ITSB Deltamas.

Diharapkan dengan membuat program dan kriteria desain yang sesuai dengan kebutuhan dan keinginan sivitas akademik sebagai end user, akan tercipta rancangan ruang ruang luar kampus yang memiliki tiga nilai keberhasilan ruang publik ${ }^{1)}$, yaitu:

1. tanggap terhadap keinginan dan kebutuhan penggunanya (responsive),

2. memiliki ikatan emosi dengan pengguna (meaningful),

3. dapat dimanfaatkan oleh seluruh sivitas akademik (democratic). 


\section{METODE}

Penelitian persepsi dan harapan bertujuan untuk merumuskan kebutuhan dan keinginan sivitas akademik terhadap ruang luar kampus ITSB Deltamas dengan mencari jenis aktivitas dan fasilitas yang paling sesuai dengan kebutuhan dan keinginan sivitas akademik. Secara umum metode yang diterapkan dalam proses penelitian yaitu penelitian deskriptif yang bersifat kualitatif dan kuantitatif. Penelitian berlandaskan pada kriteria keberhasilan ruang luar kampus yang mengacu pada kajian literatur untuk mengungkap fungsi yang paling diinginkan dan dibutuhkan sivitas akademik. Penelitian kuantitatif dengan pembagian kuesioner untuk menghindari terjadinya salah interpretasi.

Kuesioner dibagikan kepada responden yang dianggap mewakili end user ruang luar kampus ITSB Deltamas. End user ruang luar kampus yang dimaksud di sini adalah sivitas akademik, yang terdiri dari:

1. Mahasiswa/i

2. Staf pengajar

3. Staf kampus(tendik) ITSB Deltamas

Kuesioner dibagikan kepada 100 orang responden dengan komposisi:

1. 80 orang mahasiswa/i (80\%) tingkat 1 s.d. 4 dengan masing-masing 20 responden per angkatan.

2. 11 orang staf pengajar/dosen (11\%). Diambil satu staf pengajar dari 11 prodi yang ada di ITSB.

3. Sembilan orang staf kampus/tendik (9\%).

Pembagian kuesioner dilakukan dalam beberapa tahap. Jumlah ini hanya mewakili 13$15 \%$ dari jumlah total sivitas akademik ITSB Deltamas dikarenakan keterbatasan waktu penelitian.

Kuesioner yang dipakai adalah kombinasi antara kuesioner terbuka dan tertutup yang terdiri dari beberapa pertanyaan, yang masing-masing dikelompokkan ke dalam tiga kategori data. Klasifikasi data dalam tiga kategori ini untuk memudahkan dalam menganalisis informasi yang diperoleh. Klasifikasi data dikelompokkan sebagai berikut:

1. Data responden, untuk mengetahui profil sivitas akademik yang menjadi responden. Diharapkan dari data ini diketahui secara lebih akurat gambaran pengguna lahan nantinya, sehingga optimalisasi pemanfaatan ruang luar kampus ITSB Deltamas bisa dibuat sesuai dengan karakter pengguna.

2. Data persepsi, untuk mengetahui pandangan sivitas akademik kampus ITSB Deltamas terhadap ruang luar kampus serta upaya-upaya perbaikan atau kepedulian terhadap lingkungan tempat mereka beraktivitas.

3. Data harapan, menyangkut ragam aktivitas (aktif dan pasif) yang bisa dilakukan dan fasilitas yang dapat digunakan oleh pengguna ruang luar kampus nantinya. 
Data yang diperoleh ditabulasikan menurut pengelompokannya menggunakan program Microsoft Excel. Selanjutnya, dengan menggunakan program yang sama, data dianalisis dan disajikan dalam bentuk grafik (pie chart dan bar chart), sehingga lebih mudah untuk dibaca dan diintepretasikan.

\section{PEMBAHASAN DAN DISKUSI}

Sebagian besar kampus memiliki area yang didedikasikan khusus untuk lapangan rumput, ruang hijau dan lapangan bermain. Area antarbangunannya memiliki tujuan estetika, fungsional dan simbolis. Keberadaan ruang luar kampus dan segala properti yang ada di dalamnya dapat meredam kebisingan, mengontrol debu, mengalihkan lalu lintas, memberi keamanan, menyediakan privasi sekaligus menciptakan lingkungan yang lebih menyenangkan. Lebih penting lagi, ruang luar atau lanskap kampus menjadi pondasi atau dasar bagi perencanaan kampus secara menyeluruh ${ }^{2)}$. Merencanakan ruang luar sebuah kampus tidak hanya sekadar menata atau memperindah elemen lanskap atau ruang hijaunya saja, namun juga memperhatikan fungsi ruang luar sebagai sarana pembelajaran. Perencanaan ruang luar dapat dilihat dari tiga aspek berikut ${ }^{3)}$ :

1. Aspek fungsional. Aspek perencanaan ruang luar yang dapat mengakomodir atau memfasilitasi kegiatan pembelajaran mahasiswa/i.

2. Aspek teknis. Aspek perencanaan sistem infrastruktur dan utilitas lingkungan agar dapat mendukung kegiatan yang dilakukan di luar ruang tersebut.

3. Aspek estetika. Aspek perencanaan yang menekankan pengolahan elemen-elemen biotik seperti tanaman sebagai peneduh dan pengarah, penutup tanah dan lanskap lainnya sebagai unsur keindahan.

\subsection{Profil Responden}

Dari 100 kuesioner yang dibagikan terdapat $56 \%$ responden pria dan $44 \%$ wanita dengan kelompok usia 18-23 tahun sebanyak 79\%, \& kelompok usia 24-40 tahun sebanyak $13 \%$.

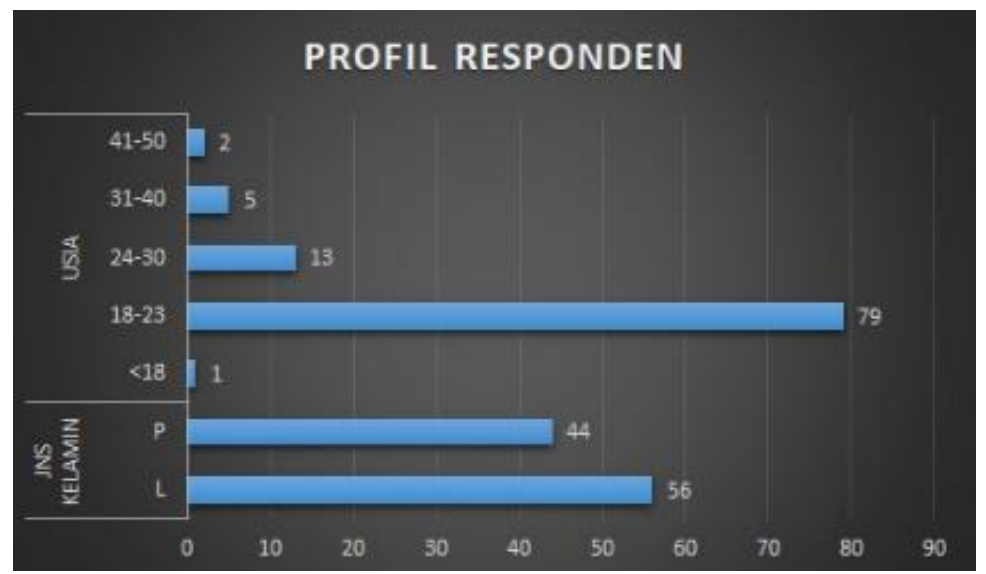

Gambar 3. Profil responden sivitas akademik ITSB Deltamas. 
Menurut pengelompokan usia remaja dari Elizabeth B. Hurlock ${ }^{4)}$, bisa disimpulkan jika pengguna ruang luar kampus ITSB Deltamas didominasi kelompok remaja dalam fase remaja akhir (late adolescence) (18-21 tahun).

Masa remaja merupakan masa perubahan, dimana terjadi perubahan-perubahan yang pesat baik secara fisik maupun psikologis, meliputi:

1. Peningkatan emosional yang terjadi secara cepat.

2. Perubahan fisik yang cepat dan disertai kematangan seksual.

3. Perubahan yang menarik bagi dirinya dan hubungan dengan orang lain.

4. Perubahan nilai.

5. Kebanyakan bersikap ambivalen dalam menghadapi perubahan - takut memikul tanggung jawab dan merasa tidak percaya diri dengan kemampuan sendiri.

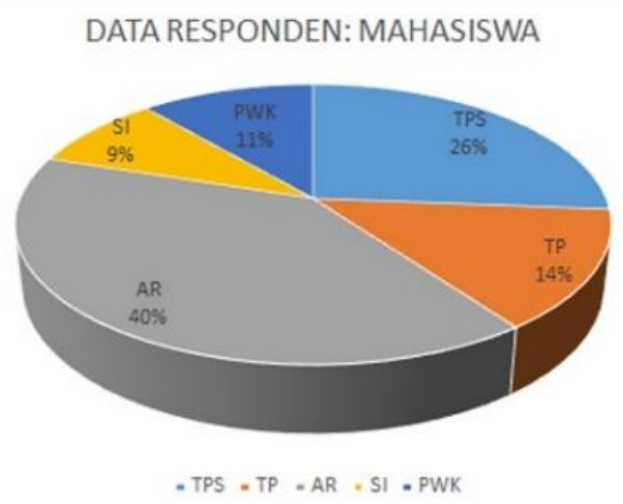

Gambar 4. Profil responden yang mewakili kelompok mahasiswa/i ITSB Deltamas.

\subsection{Data Persepsi}

Hanya $50 \%$ responden yang menyatakan betah (41\% betah dan $9 \%$ sangat betah) beraktivitas di ruang luar (halaman kampus ITSB). Tingkat kebetahan menurut sivitas akademik ITSB dikarenakan:

1. Suasananya yang lapang dan terbuka (90\%), bebas memandang (88\%), dan tenang $(83 \%)$.

2. Fasiltasnya yang bersih (80\%), lengkap dan beragam (74\%), juga terawat dengan baik $(66 \%)$.

Meski demikian, lebih banyak responden (62\%) mengatakan jika fasilitas ruang luar kampus ITSB belum mencukupi dan memadai bagi penggunanya. 


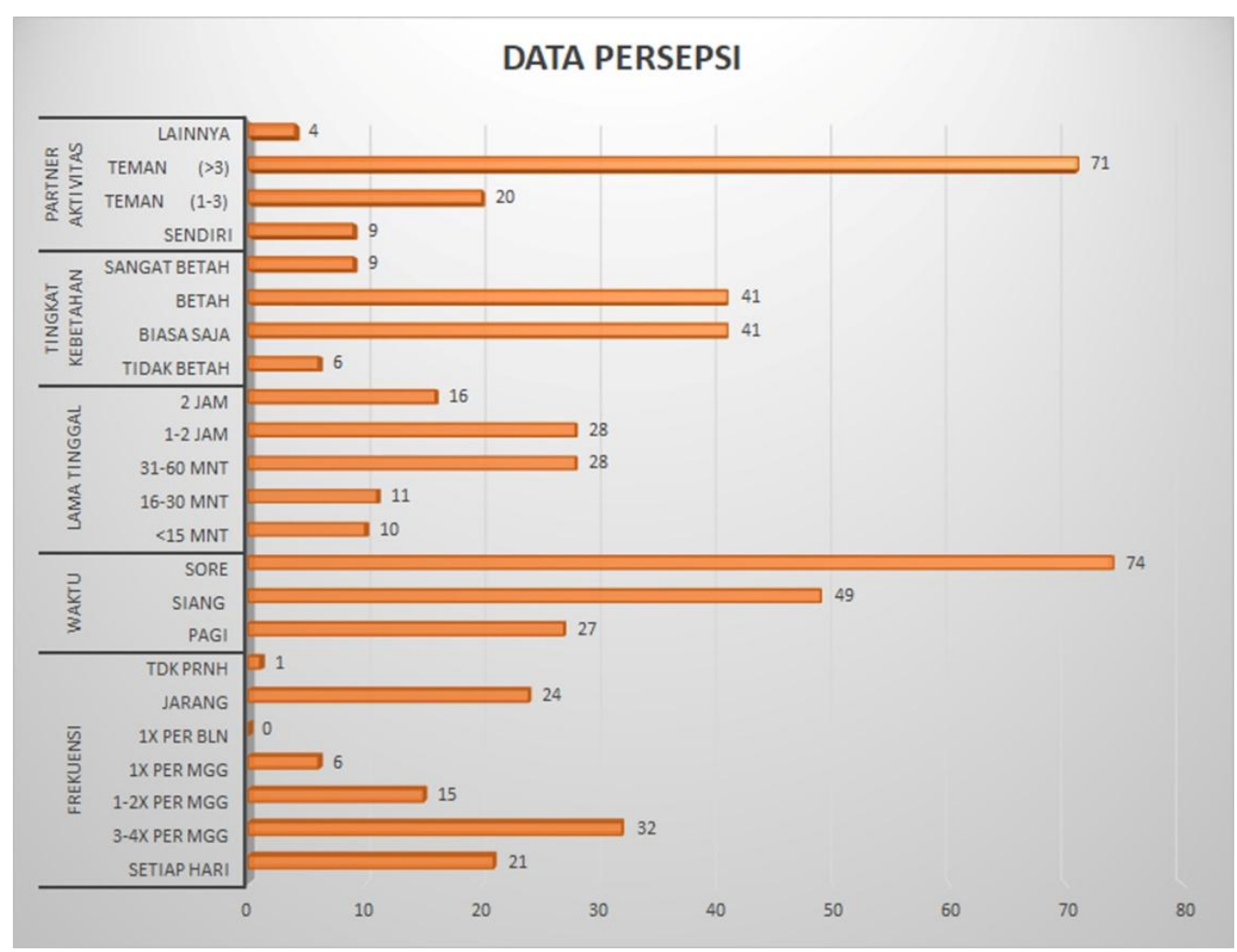

Gambar 5. Analisis tingkat kebetahan dan penggunaan ruang luar kampus ITSB Deltamas.

Frekuensi penggunaan ruang luar atau aktivitas terbanyak adalah 3-4 kali dalam seminggu (32\%). Namun, ketiga kelompok responden memiliki frekuensi penggunaan ruang ruang luar kampus yang berbeda-beda dimana kelompok staf pengajar/dosen (50\%) dan kelompok staf kampus/tendik (50\%) sama-sama jarang beraktivitas di halaman kampus. Sangat berbeda dengan kelompok mahasiswa yang frekuensi penggunaan ruangnya cukup tinggi, yakni 3-4 kali dalam seminggu (30\%).

Untuk waktu dan lama penggunaan ruang luar, kelompok staf pengajar/dosen dan staf kampus memiliki kemiripan. Kedua kelompok tersebut sama-sama beraktivitas pada siang hari di ruang luar. Kelompok staf pengajar/dosen menghabiskan waktu rata-rata aktivitas kurang dari 15 menit (70\%), sedangkan staf kampus/tendik kurang dari 30 menit (50\%). Kelompok mahasiswa lebih banyak beraktivitas di sore hari dengan durasi 31 menit-1 jam (26\%) dan 1-2 jam (27\%).

Semua kelompok responden memilih tidak beraktivitas sendirian, namun beramai-ramai bersama dengan teman-teman yang jumlahnya lebih dari tiga orang (72\%). Aktivitas pasif yang paling banyak dilakukan di sini oleh responden: diskusi (46\%), belajar (37\%), dan ngobrol (23\%). Sementara, itu kegiatan makan dan minum (46\%) serta olahraga (19\%) menjadi aktivitas aktif favorit sivitas akademik ITSB di ruang luar kampus. 


\subsection{Data Harapan}

Dalam penelitian di kampus Universitas Berkeley seperti ditulis B. Sumardiyanto dalam Prosiding Ruang Luar Kampus Evaluasi Purnahuni Dengan Studi Kasus Kampus UAJY diketahui bahwa mahasiswa mampu dengan cepat menemukan tempat-tempat yang mereka sukai (favorit) ${ }^{5)}$. Tempat-tempat favorit tersebut secara berturut-turut adalah: tempat yang alami (banyak pepohonan), tempat yang tenang, tempat yang teduh, tempat di mana orang dapat saling memandang, tempat yang dekat dengan air, tempat dengan rumput dan terbuka, tempat yang menawarkan kebebasan dan kenyamanan.

Dari penelitian yang dilakukan di kampus ITSB Deltamas terdapat urutan hasil yang berbeda mengenai preferensi ruang luar favorit. Bagi sivitas akademik ITSB Deltamas, suasana ruang luar kampus yang diharapkan sebagai berikut:

1. Bebas dan nyaman $(20 \%)$

2. Alami (banyak pepohonan) (18\%)

3. Teduh $(17 \%)$

4. Tenang (14\%)

5. Berumput dan terbuka $(18 \%)$

6. Dekat dengan air $(20 \%)$

7. Bisa saling memandang $(21 \%)$

Selain aktivitas pasif: diskusi, belajar dan berbincang-bincang/ngobrol yang sudah kerap dilakukan di ruang luar kampus ITSB; responden menginginkan ruang-ruang dengan fasilitas yang dapat digunakan untuk menikmati suasana $(88 \%)$, beristirahat (82\%), mengamati sesuatu (68\%) dan duduk-duduk (67\%). Untuk jenis aktivitas aktif, responden menginginkan kegiatan berjalan-jalan $(69 \%)$ dan bermain $(59 \%)$ bisa dilakukan di ruang luar kampus ITSB. 


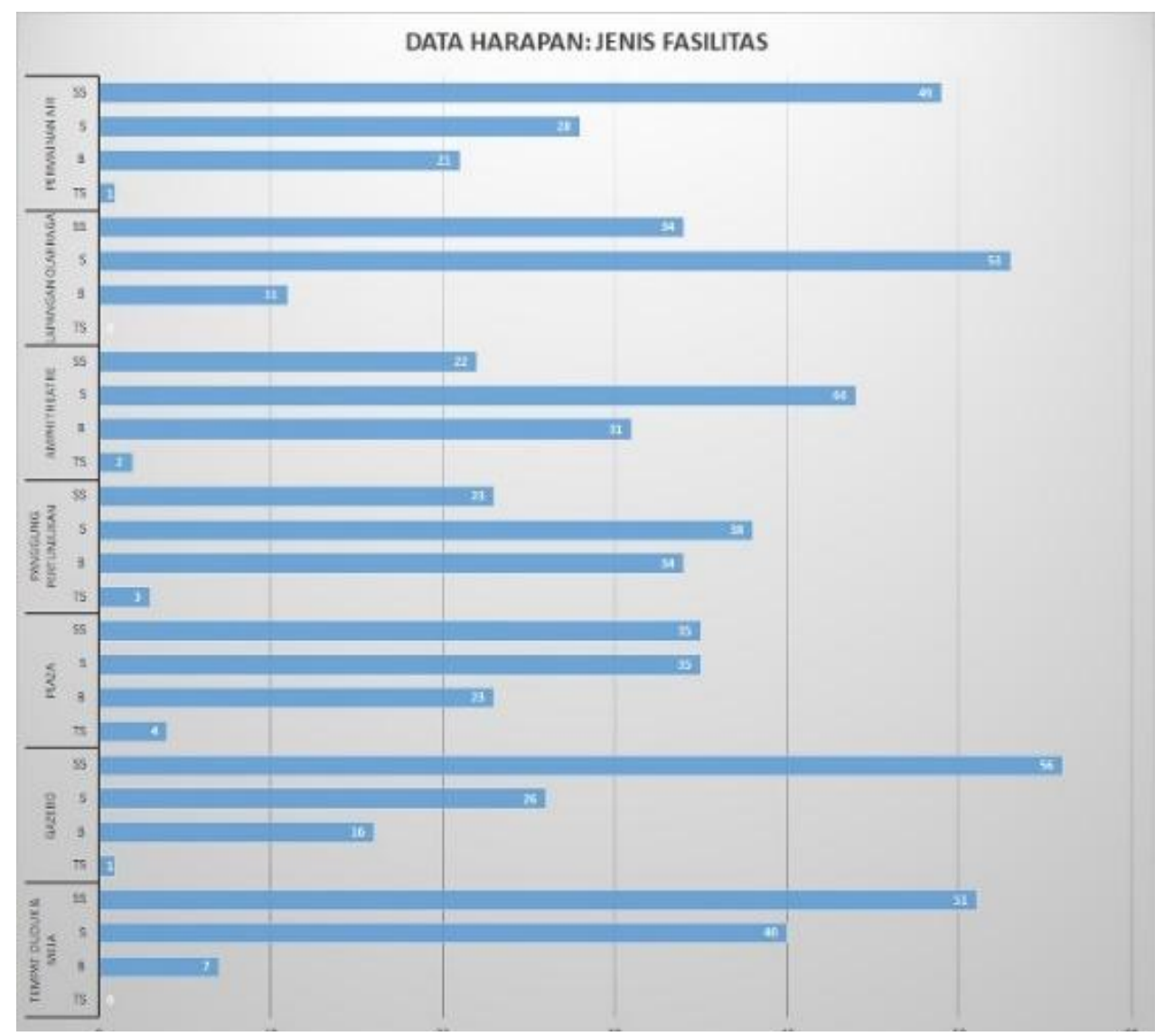

Gambar 6. Analisis jenis fasilitas ruang luar yang paling diinginkan oleh sivitas akademik ITSB Deltamas.

Kampus ITSB Deltamas sudah memiliki fasilitas ruang luar berupa plaza berukuran sedang yang dilengkapi dengan meja dan bangku panjang tanpa sandaran punggung dan tangan, serta lapangan olahraga untuk basket. Responden lebih menyukai tempat duduk yang lebih formal, dimana mereka lebih memilih meja yang dilengkapi bangku (98\%) dibanding bangku saja. Alasan paling banyak adalah agar lebih mudah dan nyaman dalam berkegiatan di ruang luar, serta memiliki tempat untuk meletakkan barang yang dibawa baik itu laptop, makanan-minuman, maupun buku-buku.

Tempat duduk yang disukai yang memiliki sandaran punggung $(85 \%)$ dengan tipe sandaran favorit, dinding bangunan (35\%) dan pohon (29\%). Bisa diartikan bahwa sivitas akademik lebih menyukai penempatan tempat duduk yang berdekatan dengan bangunan (tempat beraktivitas) serta tempat yang teduh (memiliki naungan/pembayangan). Lokasi di tempat yang terlihat (65\%) merupakan yang dominan dipilih oleh responden. Selain faktor keamanan, keinginan untuk membaur dan beraktivitas dengan yang lain menjadi alasan utama responden memilih tempat duduk diletakkan di lokasi yang terlihat. Sementara itu, 
sandaran tangan tidak menjadi perhatian utama dari responden. Terbukti yang memilih tempat duduk yang bersandaran tangan (45\%) dan tanpa sandaran tangan (42\%) cukup berimbang.

Dengan plaza yang dimiliki sekarang, responden juga merasa cukup puas. Terbukti, mereka tetap menginginkan plaza berukuran sedang. Hanya saja, mereka ingin adanya permainan air (40\%) yang mengisi plaza kampus. Di luar fasilitas olahraga lapangan basket, responden paling menginginkan ketersediaan lapangan bulutangkis (24\%). Ada pula yang menyebut jika lapangan multifungsi yang bisa digunakan untuk beragam kegiatan olahraga lebih pas untuk ruang luar kampus ITSB. Lainnya, menyukai adanya trek lari (jogging) dan sarana wall climbing di ruang luar kampus ITSB.

Selain ketiga fasilitas tersebut, fasilitas ruang lainnya yang paling diinginkan responden adalah gazebo/saung (82\%) dan permainan air (77\%). Kapasitas gazebo paling disukai yang berukuran sedang yang bisa menampung 5-8 orang $(45 \%)$ dan besar yang muat ditempati lebih dari $>8$ orang (44\%). Dengan jumlah responden yang hampir sama, menyediakan salah satu saung, apakah yang berukuran sedang atau besar, sudah bisa memenuhi harapan sivitas akademik.

\section{KESIMPULAN}

Pengguna ruang luar kampus ITSB terbanyak adalah kelompok usia remaja dalam fase remaja akhir (late adolescence). Dugaan awal peneliti bahwa ruang luar kampus Deltamas belum optimal pemanfaatannya bisa dibuktikan melalui hasil analisis data persepsi responden, dimana:

1. Ruang luar kampus ITSB Deltamas belum membuat penggunanya betah untuk beraktivitas.

2. Fasilitas ruang luar kampus ITSB belum mencukupi dan memadai bagi pengguna.

3. Minimnya variasi/ragam aktivitas (aktif dan pasif) yang bisa dilakukan oleh sivitas akademik di ruang luar kampus ITSB.

Rekomendasi untuk program dan kriteria desain ruang luar kampus ITSB Deltamas:

1. Penyediaan fasilitas ruang luar sebaiknya diprioritaskan untuk kelompok mahasiswa, tanpa mengabaikan kebutuhan kelompok staf pengajar/dosen dan staf kampus/tendik.

2. Menyediakan lebih banyak ruang-ruang aktivitas dengan fasilitas yang dapat digunakan bersama-sama secara berkelompok dengan besar kelompok lebih dari tiga orang.

3. Memprioritaskan penyediaan ruang dan fasiltas untuk aktivitas diskusi, belajar, berbincang santai/ngobrol, makan-minum, dan olahraga. Jika sudah bisa dipenuhi, selanjutnya menyediakan ruang dan fasilitas untuk menikmati suasana, istirahat, mengamati sesuatu, dan duduk-duduk. Juga memfasilitasi kegiatan berjalan-jalan dan bermain.

4. Suasana ruang luar kampus harus bebas dan nyaman, alami serta teduh. 
5. Mengutamakan penyediaan meja dan tempat duduk dengan sandaran punggung yang ditempatkan di lokasi yang berdekatan dengan bangunan/tempat beraktivitas, pada lokasi yang teduh dan terlihat oleh yang lain.

6. Untuk mewadahi keinginan sivitas akademik kampus yang beragam, lapangan basket dapat dialihfungsikan menjadi lapangan olahraga multifungsi sehingga lebih banyak ragam olahraga yang bisa dilakukan.

7. Tetap mempertahankan ukuran plaza (tidak menambah luasan) dan menambahkan permainan air.

8. Penyediaan gazebo/saung bisa yang berukuran sedang dengan kapasitas 5-8 orang atau ukuran besar untuk lebih dari 8 orang.

Saran untuk pengembangan penelitian: penambahan jumlah responden dengan sebaran kuesioner yang lebih merata dan mewakili seluruh sivitas akademik ITSB Deltamas. Dalam penelitian ini, kuesioner untuk kelompok responden mahasiswa/i baru mewakili lima prodi yang ada di ITSB. Agar dapat memberikan rekomendasi program dan kriteria desain ruang luar kampus ITSB yang lebih akurat, sebaran kuesioner bisa mencakup seluruh mahasiswa/i yang terdapat di enam prodi lainnya (TPP, TPF, TMM, TM, DI, DP) yang belum terwakili dalam penelitian ini.

\section{UCAPAN TERIMA KASIH}

Penulis mengucap syukur atas kelancaran penelitian dan penulisan kepada Tuhan YME. Tak lupa ucapan terima kasih sebesar-besarnya kepada ITSB dan LPPM ITSB sebagai penyedia dana penelitian, serta seluruh sivitas akademik ITSB, rekan dosen, tendik, dan mahasiswa/i yang membantu penulis dalam merampungkan penelitian dan penulisan laporan.

\section{DAFTAR PUSTAKA}

1) Carr, Stephen. Francis, Mark. Rivlin, Leanne G., Stone, Andrew M. (1992). Public Space, New York, Cambridge University Press.

2) Dober, Richard P. (1992). Campus Design, USA, John Wiley \& Sons, Inc.

3) Hatmoko, Adi Utomo. Wulandari, Wahyu. Alhamdani, Muhamad Ridha. Lionar, Mario Ledeweik (2014). Arsitektur Fasilitas Pendidikan; Yogyakarta.

4) Hurlock, Elizabeth B (2003). Psikologi Perkembangan, Jakarta, Erlangga; hal. 206.

5) Sumardiyanto, B (2010). Prosiding Konferensi Teknik Sipil: Ruang Luar Kampus Evaluasi Purnahuni Dengan Studi Kasus Kampus UAJY, Sanur Bali. 